\title{
Physiological Traits Associated with Wheat Yield Potential and Performance under Water-Stress in a Mediterranean Environment
}

\author{
Alejandro del Pozo ${ }^{1 *}$, Alejandra Yáñez ${ }^{1,2}$, Iván A. Matus ${ }^{3}$, Gerardo Tapia ${ }^{3}$, Dalma Castillo $^{3}$, \\ Laura Sanchez-Jardón ${ }^{4}$ and José L. Araus ${ }^{5}$ \\ 'Programa de Investigación de Excelencia Interdisciplinaria, Adaptación de la Agricultura al Cambio Climático (A2C2), \\ Facultad de Ciencias Agrarias, Centro de Mejoramiento Genético y Fenómica Vegetal, Universidad de Talca, Talca, Chile, \\ ${ }^{2}$ Departamento de Ciencias Agrarias, Facultad de Ciencias Agrarias y Forestales, Universidad Católica del Maule, Curicó, \\ Chile, ${ }^{3}$ Centro Regional Investigación Quilamapu, Instituto de Investigaciones Agropecuarias, Chillán, Chile, ${ }^{4}$ Centro \\ Universitario de la Patagonia, Universidad de Magallanes, Coyhiaque, Chile, ${ }^{5}$ Unitat de Fisiologia Vegetal, Facultat de \\ Biologia, Universitat de Barcelona, Barcelona, Spain
}

\section{OPEN ACCESS}

Edited by:

Edmundo Acevedo,

University of Chile, Chile

Reviewed by:

Agata Gadaleta,

University of Bari, Italy

Cándido López-Castañeda,

Colegio de Postgraduados, Mexico

*Correspondence:

Alejandro del Pozo

adelpozo@utalca.c

Specialty section:

This article was submitted to Crop Science and Horticulture,

a section of the journal

Frontiers in Plant Science

Received: 17 May 2016

Accepted: 21 June 2016

Published: 07 July 2016

Citation:

del Pozo A, Yáñez A, Matus IA,

Tapia G, Castillo D, Sanchez-Jardón L and Araus JL (2016) Physiological Traits Associated with Wheat Yield Potential and Performance under Water-Stress in a Mediterranean Environment. Front. Plant Sci. 7:987. doi: 10.3389/fpls.2016.00987
Different physiological traits have been proposed as key traits associated with yield potential as well as performance under water stress. The aim of this paper is to examine the genotypic variability of leaf chlorophyll, stem water-soluble carbohydrate content and carbon isotope discrimination $\left(\Delta^{13} \mathrm{C}\right)$, and their relationship with grain yield (GY) and other agronomical traits, under contrasting water conditions in a Mediterranean environment. The study was performed on a large collection of 384 wheat genotypes grown under water stress (WS, rainfed), mild water stress (MWS, deficit irrigation), and full irrigation (FI). The average GY of two growing seasons was 2.4, 4.8, and $8.9 \mathrm{Mg} \mathrm{ha}^{-1}$ under WS, MWS, and FI, respectively. Chlorophyll content at anthesis was positively correlated with GY (except under FI in 2011) and the agronomical components kernels per spike (KS) and thousand kernel weight (TKW). The WSC content at anthesis (WSCCa) was negatively correlated with spikes per square meter (SM2), but positively correlated with KS and TKW under WS and FI conditions. As a consequence, the relationships between WSCCa with GY were low or not significant. Therefore, selecting for high stem WSC would not necessary lead to genotypes of GY potential. The relationship between $\Delta^{13} \mathrm{C}$ and GY was positive under FI and MWS but negative under severe WS (in 2011), indicating higher water use under yield potential and MWS conditions.

Keywords: carbohydrate, carbon isotope discrimination, chlorophyll, drought, stem reserves

\section{INTRODUCTION}

Since the Green Revolution the yields of wheat and other cereals have increased considerably in many regions of the world, including Chile (Calderini and Slafer, 1998; Engler and del Pozo, 2013; del Pozo et al., 2014), as a result of genetic improvement and better agronomic practices. The yield potential, i.e., the yield achieved when the best available technology is used, has also increased almost linearly since the sixties, particularly in more favorable environments where soil water availability is not limited (Zhou et al., 2007; Fischer and Edmeades, 2010; Matus et al., 2012; del Pozo et al., 2014). Yield under water-limiting conditions, such those of the rainfed 
Mediterranean environments, has also increased during the past decades (Sánchez-García et al., 2013). Notwithstanding the possible need for phenological adjustment (earliness) a higher yield potential may also translate into a higher performance under water stress (Nouri et al., 2011; Hawkesford et al., 2013). However, the potential yield and water-limited yield of wheat needs to continue increasing in order to cope with future demand for food, which is a consequence of the growing population and changes in social habits (Fischer, 2007; Hawkesford et al., 2013), and also to reduce the negative impacts on crop productivity of global climate change (Lobell et al., 2008; Lobell and Gourdji, 2012).

The increase, in the yield potential and stress adaptation of wheat has been attained mainly through empirical selection for grain yield (GY). However, there is evidence that phenotyping using physiological traits, as a complement to agronomic traits, may help in identifying selectable features that accelerate breeding for yield potential and performance under drought (Araus et al., 2002, 2008; Fischer, 2007; Foulkes et al., 2007; Cattivelli et al., 2008; Fleury et al., 2010). The increases in yield potential of wheat since the sixties have been both positively correlated with shoot dry matter and harvest index (HI); the latter also being positively associated with water-soluble carbohydrate (WSC) content of stems at anthesis (Foulkes et al., 2007). Under water limiting conditions, various physiological process and traits have been associated with GY (e.g., Araus et al., 2002, 2008; Condon et al., 2004; Reynolds et al., 2006; Tambussi et al., 2007). Among them are traits related to pre-anthesis accumulation of WSC in stems and its further use during grain filling (Ehdaie et al., 2006a,b; Reynolds et al., 2006), delays in senescence during grain filling assessed via changes in leaf color (Lopes and Reynolds, 2012), and those related to water use efficiency, in particular carbon isotope discrimination $\left(\Delta^{13} \mathrm{C}\right)$ in kernels (Richards et al., 2002; Araus et al., 2003, 2008).

WSCs are accumulated in stems prior to anthesis and then are remobilized to the grain during the grain-filling period (Blum, 1998; Bingham et al., 2007). Under water limiting conditions, where canopy photosynthesis is inhibited, the contribution of stem carbohydrate to grain growth could be very significant (Ehdaie et al., 2006a,b; Reynolds et al., 2006). Both spring and winter wheat lines have been shown to vary significantly for WSC concentration and WSC content in stems around anthesis (Ruuska et al., 2006; Foulkes et al., 2007; Yang et al., 2007), whereas positive correlations have been observed between accumulated WSC at anthesis and GY in winter wheat genotypes (Foulkes et al., 2007), as well as with kernel weight in recombinant inbred lines (RILs) from the Seri/Babax population (Dreccer et al., 2009). However, stem WSC concentrations can be negatively correlated with stem number $\mathrm{m}^{-2}$ (Dreccer et al., 2013).

Drought increases senescence, by accelerating chlorophyll degradation, leading to a decrease in leaf area and canopy photosynthesis. There is evidence that stay-green phenotypes with delayed leaf senescence can improve their performance under drought conditions (Rivero et al., 2007; Lopes and Reynolds, 2012).

$\Delta^{13} \mathrm{C}$ can be used as a selection criterion for high water use efficiency (Condon et al., 2004; Richards, 2006), but also can provide an indirect determination of the effective water used by the crop (Araus et al., 2002, 2008; Blum, 2009). In fact,

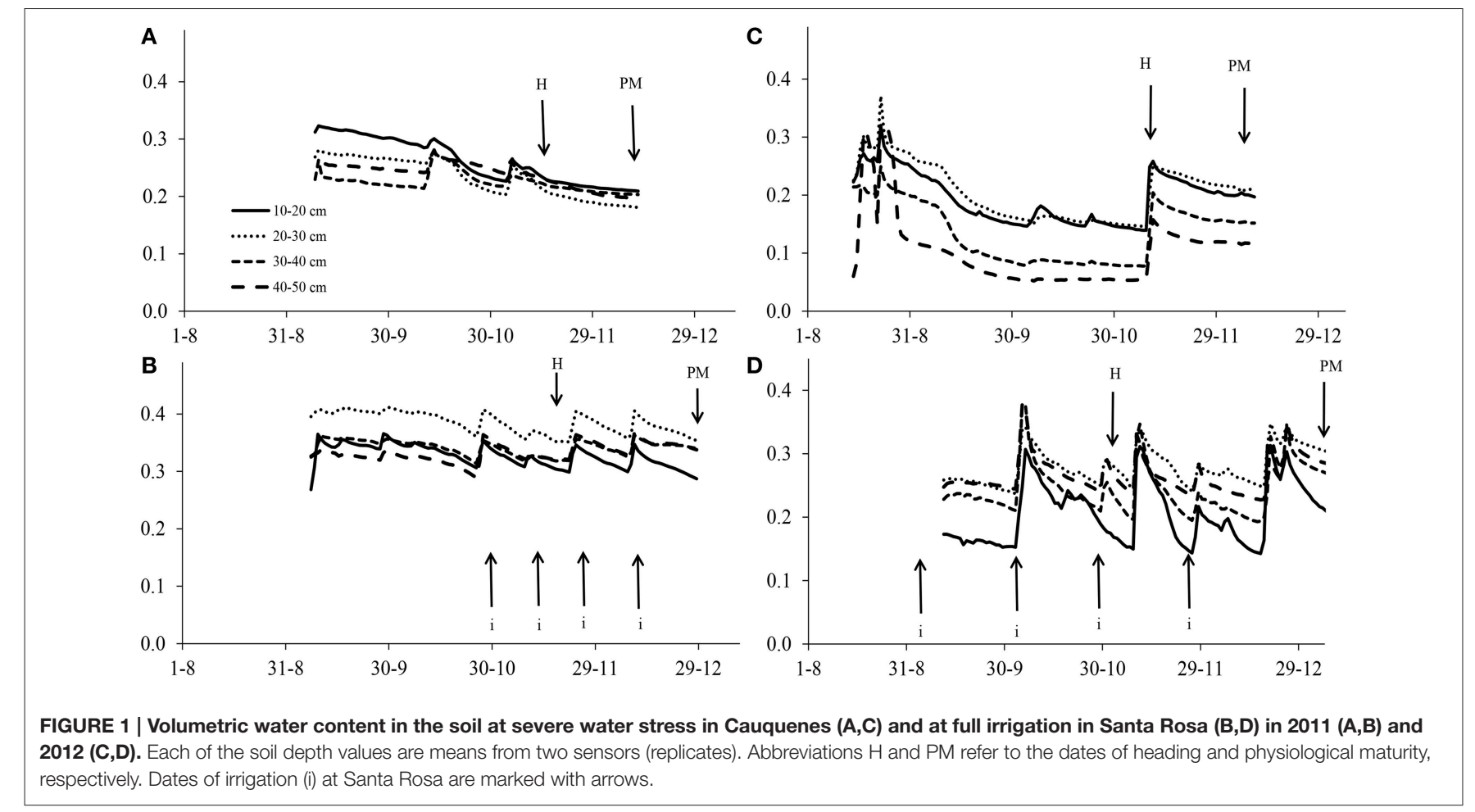


kernel $\Delta^{13} \mathrm{C}$ can be positively or negatively correlated with GY depending on soil water availability. Indeed, under moderate stress to well-watered Mediterranean conditions $\Delta^{13} \mathrm{C}$ has been reported to be positively correlated with GY in wheat (Araus et al., 2003, 2008 for wheat) and barley (Acevedo et al., 1997; Voltas et al., 1999; del Pozo et al., 2012), whereas the opposite trend has been reported under severe drought conditions (but see Araus et al., 1998).

In this study we investigated the genotypic variability of flag leaf chlorophyll content (measured with a portable leaf meter), stem WSC accumulation at anthesis and the $\Delta^{13} \mathrm{C}$ of mature kernels, as well as the relationship of these traits with GY and its agronomical components, in spring bread wheat under contrasting water conditions in a Mediterranean environment. It is hypothesized that within a large set (384 genotypes) cultivars and advanced lines of spring bread wheat there is high genotypic variability for agronomic and physiological traits. In addition, the yield performance of genotypes under drought conditions is associated with stem WSC accumulation, delayed leaf senescence, and carbon discrimination in grains.

\section{MATERIALS AND METHODS}

\section{Plant Material and Growing Conditions}

A collection of 384 cultivars and advanced semidwarf lines of spring bread wheat (Triticum aestivum L.), including 153 lines from the wheat breeding program of the Instituto de Investigaciones Agropecuarias (INIA) in Chile, 53 from the International Wheat and Maize Improvement Centre (CIMMYT) that were previously selected for adaptiveness to Chilean environments (these lines share common ancestors with the INIA-Chile breeding program), and 178 lines from INIA in Uruguay (Table S1). The objective with this set of lines was to create a germplasm base to breed for drier areas in Chile and subsequently other countries within the projects involved.

This large set of genotypes was evaluated in two Mediterranean sites of Chile: Cauquenes $\left(35^{\circ} 58^{\prime} \mathrm{S}, 72^{\circ} 17^{\prime}\right.$ W; 177 m.a.s.l.) under the water stress (WS) typical of the rainfed at this site, and Santa Rosa $\left(36^{\circ} 32^{\prime}\right.$ S, $71^{\circ} 55^{\prime}$ W; 220 m.a.s.l.) under full irrigation (FI) and moderate water stress (MWS) conditions achieved through support irrigation. Trials were assayed during two consecutive (2011 and 2012) crop seasons, except for the MWS trial, which was only set up during 2011. Cauquenes corresponds to the Mediterranean drought-prone area of Chile; the average annual temperature is $14.7^{\circ} \mathrm{C}$, the minimum average is $4.7^{\circ} \mathrm{C}$ (July) and the maximum is $27^{\circ} \mathrm{C}$ (January). The evapotranspiration is $1200 \mathrm{~mm}$ (del Pozo and del Canto, 1999) and the annual precipitation was 410 and $600 \mathrm{~mm}$ in 2011 and 2012, respectively. Santa Rosa corresponds to a high yielding area; the average annual temperature in this region is $13.0^{\circ} \mathrm{C}$, the minimum average is $3.0^{\circ} \mathrm{C}$ (July) and the maximum is $28.6^{\circ} \mathrm{C}$ (January; del Pozo and del Canto, 1999). The annual precipitation was 736 and $806 \mathrm{~mm}$, in 2011 and 2012, respectively.

The experimental design was an $\alpha$-lattice with 20 incomplete blocks per replicate, each block containing 20 genotypes. In each replicate two cultivars (Don Alberto and Carpintero) were included eight times. Two replicates per genotypes were used, except at Cauquenes and Santa Rosa SI in 2011 where a single replicate was established. Plots consisted of five rows of $2 \mathrm{~m}$ in length and $0.2 \mathrm{~m}$ distance between rows. The sowing rate was 20 $\mathrm{g} \mathrm{m}^{2}$ and sowing dates were: 07 September and 23 May, in 2011 and 2012, respectively at Cauquenes; 31 and 7 August, in 2011 and 2012, respectively at Santa Rosa. Because the sowing date in 2011 at Cauquenes was much later than in 2012, the water stress was more severe in the first year. Plots were fertilized with $260 \mathrm{~kg}$ $\mathrm{ha}^{1}$ of ammonium phosphate $\left(46 \% \mathrm{P}_{2} \mathrm{O}_{5}\right.$ and $\left.18 \% \mathrm{~N}\right), 90 \mathrm{~kg} \mathrm{ha}^{-1}$ of potassium chloride $\left(60 \% \mathrm{~K}_{2} \mathrm{O}\right), 200 \mathrm{~kg} \mathrm{ha}^{-1}$ of sul-po-mag $\left(22 \% \mathrm{~K}_{2} \mathrm{O}, 18 \% \mathrm{MgO}\right.$, and $\left.22 \% \mathrm{~S}\right), 10 \mathrm{~kg} \mathrm{ha}^{-1}$ of boronatrocalcite $(11 \% \mathrm{~B})$, and $3 \mathrm{~kg} \mathrm{ha}^{-1}$ of zinc sulfate (35\% Zn). Fertilizers were incorporated with a cultivator before sowing. During tillering an extra $153 \mathrm{~kg} \mathrm{ha}^{-1}$ of $\mathrm{N}$ was applied. Weeds were controlled with the application of Flufenacet + Flurtamone + Diflufenican (96 $\mathrm{g}$ a.i.) as pre-emergence controls and a further application of MCPA (525 g a.i.) + Metsulfuron-metil (5 g a.i.) as postemergents. Cultivars were disease resistance and no fungicide was used.

Furrow irrigation was used in Santa Rosa: one irrigation at the end of tillering (Zadocks Stage 21; Zadoks et al., 1974) in the

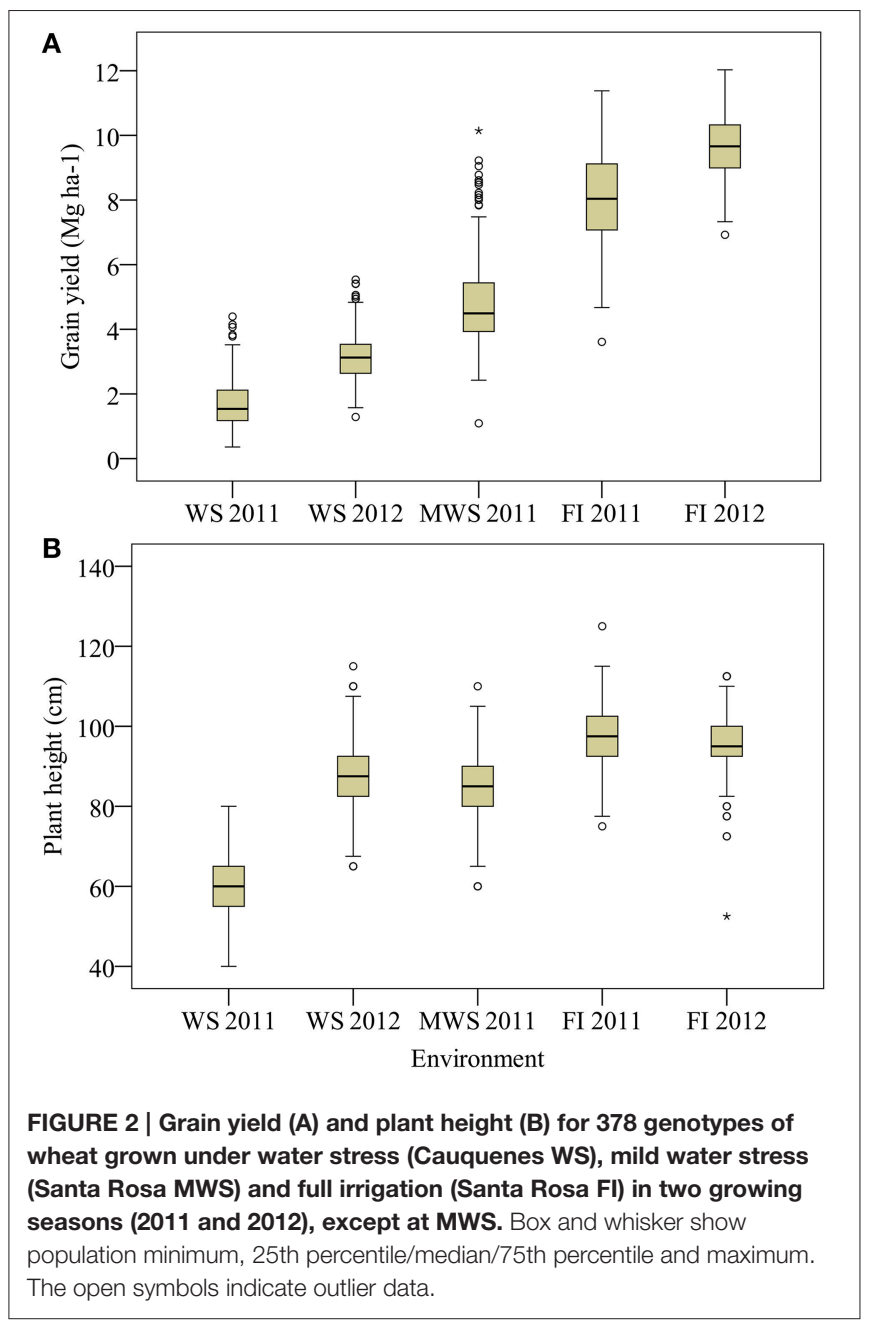


MWS trial and four irrigations at the end of tillering, the flag leaf stage (Z37), heading (Z50), and middle grain filling (Z70) in the FI trial respectively. Soil moisture at 10-20, 20-30, 30-40, and $40-50 \mathrm{~cm}$ depth was determined by using 10HS sensors (Decagon Devices, USA) connected to an EM-50 data logger (Decagon Devices, USA). The 10HS sensor determines volumetric water content by measuring the dielectric constant of the soil using capacitance/frequency domain technology. Two sets of sensors were set up in each environment and mean values of two sensors per depth are presented in Figure 1.

\section{Agronomical Traits}

Days from emergence to heading (DH) were determined in Santa Rosa, through periodic (twice a week) observations, when approximately half of the spikes in the plot had already extruded. At maturity and for each plot the plant height $(\mathrm{PH})$ of the different trials, up to the extreme of the spike (excluding awns), was measured, the number of spikes per $\mathrm{m}^{2}$ (SM2) were determined for a $1 \mathrm{~m}$ length of an inside row, and the number of kernels per spike (KS) and 1000 kernel weight (TKW) were determined in 25 spikes taken at random. Grain yield was assessed by harvesting the whole plot.

\section{Leaf Chlorophyll Content and Water-Soluble Carbohydrates}

Chlorophyll content (SPAD index) was determined at anthesis and then during grain filling about 2 weeks after anthesis (both measured on given calendar dates) in five flag leaves per plot using a SPAD 502 (Minolta Spectrum Technologies Inc., Plainfield, IL, USA) portable leaf chlorophyll meter. WSC concentration in stems (harvested at ground level and excluding leaf laminas and sheaths) was determined at anthesis and maturity, on five main stems per plot, using the anthrone reactive method (Yemm and Willis, 1954). The stem length was measured and then dried for $48 \mathrm{~h}$ at $60^{\circ} \mathrm{C}$, weighed and ground. Next, a $100 \mathrm{mg}$ subsample was used for WSC extraction, with $3 \mathrm{ml}$ of extraction buffer containing $80 \%$ ethanol $10 \mathrm{mM}$ Hepes-KOH $(\mathrm{pH}=7.5)$, and incubated at $60^{\circ} \mathrm{C}$ overnight. Then, to separate the debris, the samples were centrifuged at $60 \mathrm{rpm}$ for $30 \mathrm{~min}$. The anthrone reagent was added to each supernatant and placed over a hotplate at $80^{\circ} \mathrm{C}$ for $20 \mathrm{~min}$. Finally, the absorbance of the sample was measured at $620 \mathrm{~nm}$ in an EPOCH microplate UVVis Spectrophotometer (Biotek) using COSTAR 363696 wellplates (Corning) for the UV range. WSC content per whole stem and per unit land area were calculated as WSC concentration per unit stem weight $\left(\mathrm{mg} \mathrm{CHO} \mathrm{g} \mathrm{stem}{ }^{-1}\right)$, and WSC content per unit of stem (mg CHO stem ${ }^{-1}$ ) and per unit grown area (g $\mathrm{CHO} \mathrm{\textrm {m } ^ { - 2 }}$ ), respectively. In addition, the apparent WSC remobilization was calculated as the differences from anthesis to maturity in WSC content on a stem and land area basis.

\section{Stable Carbon Isotope Analysis}

The stable carbon $\left({ }^{13} \mathrm{C} /{ }^{12} \mathrm{C}\right)$ isotope ratio was measured in mature kernels using an elemental analyser (ANCASL, PDZ Europa, UK) coupled with an isotope ratio mass spectrometer, at the Laboratory of Applied Physical Chemistry

TABLE 1 | F-values of ANOVA for agronomic and physiological traits, for $\mathbf{3 7 8}$ genotypes of wheat grown under severe water stress (Cauquenes WS) and full irrigation (Santa Rosa FI) in two growing seasons.

\begin{tabular}{|c|c|c|c|c|c|c|c|c|c|}
\hline Agronomic traits & Year & Genotype (G) & Environment (E) & $\mathbf{G} \times \mathbf{E}$ & Physiological traits & Year & Genotype (G) & Environment (E) & $G \times E$ \\
\hline GY & 2012 & $2.5^{\star \star \star}$ & $24217^{\star \star \star}$ & $1.8^{\star * \star}$ & & 2012 & $4.6^{\star \star \star}$ & $4633^{\star \star \star}$ & $2.0^{\star * \star}$ \\
\hline $\mathrm{DH}$ & 2012 & - & - & - & & 2012 & $2.4^{\star \star \star}$ & $1952^{\star \star \star}$ & $1.8^{\star \star \star}$ \\
\hline $\mathrm{PH}$ & 2011 & $4.0^{\star \star \star}$ & $12052^{\star \star \star}$ & $1.4^{* *}$ & SWa & 2011 & 0.7 & $76^{\star \star \star}$ & 0.4 \\
\hline SM2 & 2012 & $5.5^{\star \star \star}$ & $7978^{\star \star \star}$ & $2.1^{\star \star \star}$ & & 2012 & $6.2^{\star \star \star}$ & 0.9 & $1.3^{\star *}$ \\
\hline \multirow[t]{2}{*}{ KS } & 2011 & $6.6^{\star \star \star}$ & $2383^{\star \star \star}$ & $1.8^{\star \star \star}$ & WSCa & 2011 & $1.3^{\star}$ & $133^{\star \star \star}$ & 1.0 \\
\hline & 2012 & $3.8^{\star \star \star}$ & $613^{\star \star *}$ & $1.6^{\star \star \star}$ & & 2012 & $1.2^{\star}$ & $1249^{* * \star}$ & $1.2^{\star}$ \\
\hline \multirow[t]{2}{*}{ TKW } & 2011 & $15.1^{\star \star \star}$ & $6725^{\star \star \star}$ & $1.4^{* *}$ & WSCm & 2011 & $6.7^{\star * *}$ & $2963^{\star \star \star}$ & $6.6^{\star \star \star}$ \\
\hline & 2012 & $14.1^{\star \star \star}$ & $906^{\star \star \star}$ & $1.3^{\star *}$ & & 2012 & $1.5^{\star \star \star}$ & $13^{\star \star \star}$ & 1.1 \\
\hline \multirow{2}{*}{ KM2 } & & & & & $\Delta^{13} \mathrm{C}$ & 2011 & 1.1 & $7512^{\star \star \star}$ & 0.7 \\
\hline & & & & & & 2012 & $4.3^{\star \star \star}$ & $45500^{\star \star \star}$ & $1.6^{\star \star \star}$ \\
\hline
\end{tabular}

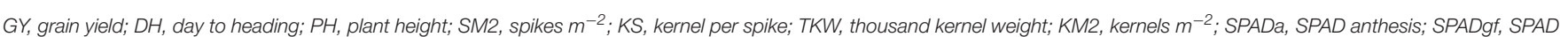

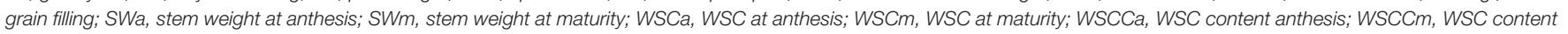
maturity; $\Delta^{13} \mathrm{C}$, kernel $\Delta^{13} \mathrm{C}$.

a In 2011, 10 genotypes were discarded from the analysis due to low spike numbers.

${ }^{\star} P<0.05 ;{ }^{* *} P<0.001 ;{ }^{* \star *} P<0.0001$. 

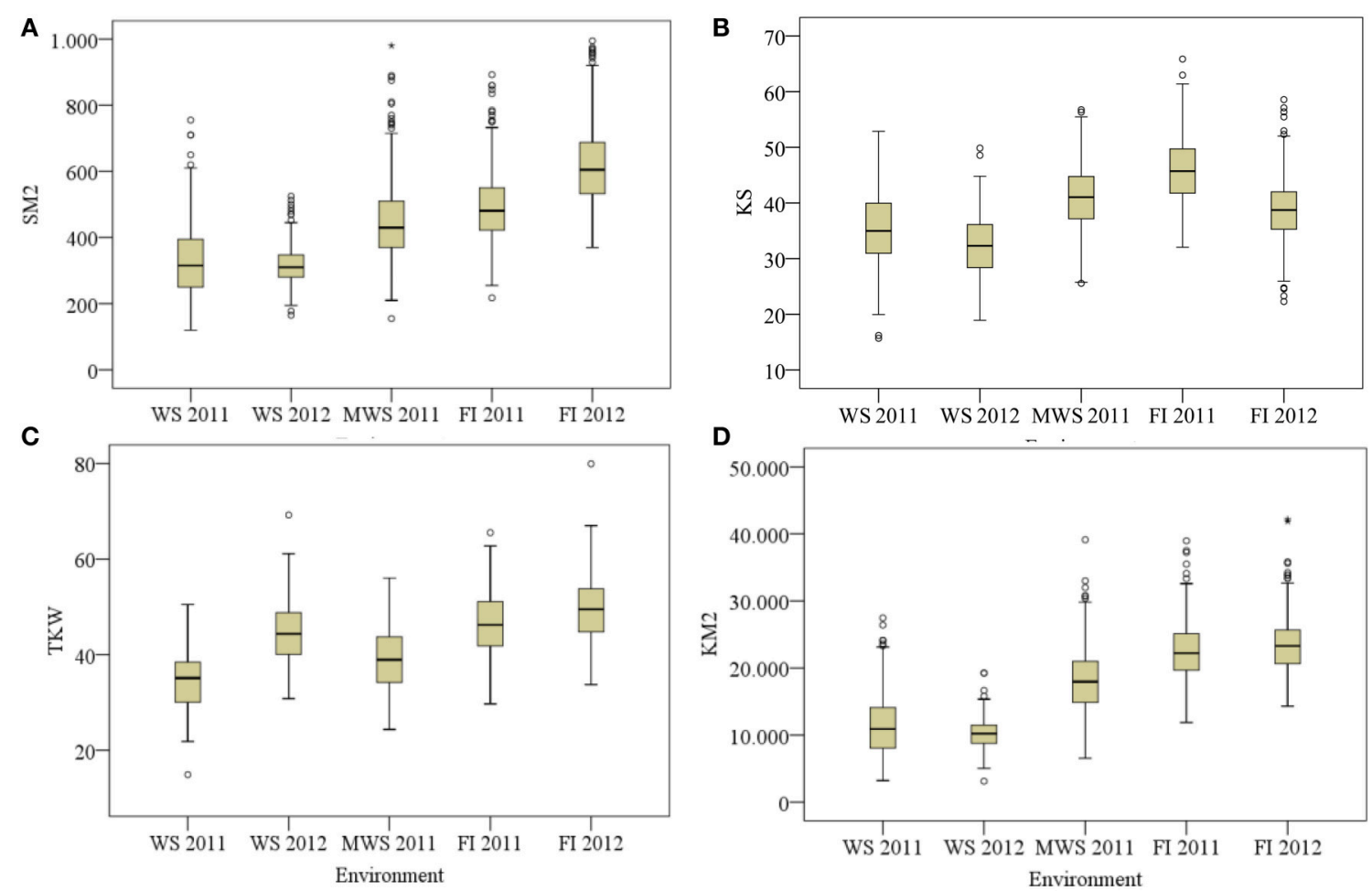

FIGURE 3 | Spikes per $\mathrm{m}^{2}$ (SM2; A), kernel per spike (KS; B), thousand kernel weight [TKW (g); C] and kernels $\mathrm{m}^{-2}$ (KM2; D) for 378 genotypes of wheat grown under water stress (Cauquenes WS), mild water stress (Santa Rosa MWS) and full irrigation (Santa Rosa FI) in two growing seasons (2011 and 2012), except at MWS. Box and whisker show population minimum, 25th percentile/median/75th percentile and maximum. The open symbols indicate outlier data.

at Ghent University (Belgium). The ${ }^{13} \mathrm{C} /{ }^{12} \mathrm{C}$ ratios were expressed in $\delta$ notation (Coplen, 2008) determined by: $\delta^{13} \mathrm{C}$ $=\left({ }^{13} \mathrm{C} /{ }^{12} \mathrm{C}\right)_{\text {sample }} /\left({ }^{13} \mathrm{C} /{ }^{12} \mathrm{C}\right)_{\text {standard }}-1$ (Farquhar et al., 1989), where sample refers to plant material and standard to the laboratory standards that have been calibrated against international standards from Iso-Analytical (Crewe, Cheshire, $\mathrm{UK})$. The precision of $\delta^{13} \mathrm{C}$ analyses was $0.3 \%$ o $(\mathrm{SD}, n=10)$. Further, the carbon isotope discrimination $\left(\Delta^{13} \mathrm{C}\right)$ of kernels was calculated as: $\Delta^{13} \mathrm{C}(\% \mathrm{o})=\left(\delta^{13} \mathrm{C}_{\mathrm{a}}-\delta^{13} \mathrm{C}_{\mathrm{p}}\right) /\left[1+\left(\delta^{13} \mathrm{C}_{\mathrm{p}}\right) / 1000\right]$, where a and $\mathrm{p}$ refer to air and the plant, respectively (Farquhar et al., 1989). $\delta^{13} \mathrm{C}_{\mathrm{a}}$ from the air was taken as $-8.0 \%$.

\section{Yield Tolerance Index}

The yield tolerance index (YTI), which combines the relative performance of a genotype under drought with its potential yield under irrigated conditions (Ober et al., 2004), was calculated as:

$$
Y T I=\left(\frac{Y_{D}}{\bar{Y}_{D}}\right)\left(\frac{Y_{I}}{\bar{Y}_{I}}\right)\left(\frac{\bar{Y}_{D}}{\bar{Y}_{I}}\right)=\left(\frac{Y_{D} Y_{I}}{\bar{Y}_{I}^{2}}\right)
$$

where $Y_{D}$ and $Y_{I}$ are the genotype mean yield under drought (Cauquenes) and irrigation conditions (Santa Rosa, fully irrigation), respectively, and $\bar{Y}_{D}$ and $\bar{Y}_{I}$ are the mean yield of all genotypes growing under drought and irrigated conditions, respectively.

\section{Statistical Analysis}

In 2011, 10 genotypes were discarded from analysis due to low emergence. In addition six genotypes from Uruguay were discarded from the analysis for having late heading time (more than 100 days) an plant height $>120 \mathrm{~cm}$. ANOVAs for physiological and yield-related traits were performed for the whole set of genotypes using PROC MIXED of the SAS Institute Inc. Genotypes and environment (Cauquenes WS and Santa Rosa FI) were considered fixed effects, whereas blocks and incomplete blocks within each replication (in an $\alpha$-lattice design) were considered random effects. Data from Santa Rosa MWS where not considered in the ANOVAs because there was no replication and only one year (2011) of observations. Correlation analysis was performed between agronomic and physiological traits, and also stepwise regressions between grain yield and related agronomical and physiological traits. Principal component analysis (PCA) was carried out for the 378 genotypes using the mean values for physiological and agronomical traits evaluated under severe water stress in Cauquenes and full irrigation in Santa Rosa, in two growing seasons, using IBM SPSS Statistics 19.

\section{RESULTS}

\section{Agronomical and Physiological Traits}

For SM2, KS and TKW the genotype $\mathrm{x}$ environment $(\mathrm{GxE})$ interaction was highly significant $(P<0.001)$ in both growing 
TABLE 2 | Means \pm standard deviation and ranges (minimum-maximum) for chlorophyll content in SPAD units, stem weight, water-soluble carbohydrate (WSC) concentration and content per stem at anthesis and maturity, and carbon isotope discrimination ( $\left.\Delta^{13} \mathrm{C}\right)$ in kernels, for 378 genotypes of wheat

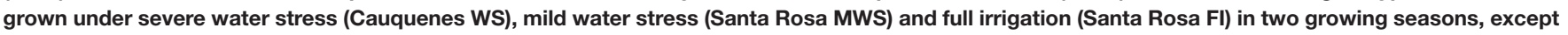
at MWS.

\begin{tabular}{|c|c|c|c|c|c|c|c|}
\hline \multirow[b]{2}{*}{ Trait } & \multirow[b]{2}{*}{ Year } & \multicolumn{2}{|c|}{ Cauquenes (WS) } & \multicolumn{2}{|c|}{ Santa Rosa (MWS) } & \multicolumn{2}{|c|}{ Santa Rosa (FI) } \\
\hline & & Mean & Range & Mean & Range & Mean & Range \\
\hline \multirow[t]{2}{*}{ Days to heading } & 2011 & n.e. & n.e. & $78 \pm 3$ & $71-86$ & $79 \pm 3$ & $73-89$ \\
\hline & 2012 & n.e. & n.e. & n.e. & n.e. & $85 \pm 4$ & $78-100$ \\
\hline \multirow[t]{2}{*}{ SPAD anthesis } & 2011 & $47 \pm 5$ & $32-60$ & $47 \pm 3$ & $34-56$ & $45 \pm 3$ & $36-52$ \\
\hline & 2012 & $42 \pm 3$ & $32-50$ & n.e. & n.e. & $49 \pm 3$ & $41-58$ \\
\hline \multirow[t]{2}{*}{ SPAD grain filling } & 2011 & n.e. & n.e. & $31 \pm 12$ & $4-52$ & $43 \pm 3$ & $30-51$ \\
\hline & 2012 & $34 \pm 8$ & $4-47$ & n.e. & n.e. & $48 \pm 3$ & $35-55$ \\
\hline \multirow[t]{2}{*}{ Stem weight anthesis (g) } & 2011 & $1.24 \pm 0.31$ & $0.50-2.44$ & $1.68 \pm 0.40$ & $0.86-2.88$ & $1.67 \pm 0.36$ & $0.91-2.84$ \\
\hline & 2012 & $1.81 \pm 0.36$ & $0.91-3.04$ & n.e. & n.e. & $1.19 \pm 0.27$ & $0.54-1.95$ \\
\hline \multirow[t]{2}{*}{ Stem weight maturity (g) } & 2011 & $0.70 \pm 0.19$ & $0.26-1.48$ & $0.98 \pm 0.26$ & $0.41-3.03$ & $1.14 \pm 0.25$ & $0.57-2.06$ \\
\hline & 2012 & $1.06 \pm 0.24$ & $0.59-1.79$ & n.e. & n.e. & $1.06 \pm 0.23$ & $0.54-2.13$ \\
\hline \multirow[t]{2}{*}{ WSC concentration anthesis $\left(\mathrm{mg} \mathrm{g}^{-1}\right)$} & 2011 & $178.4 \pm 56.0$ & $63.9-548.3$ & $152.6 \pm 40.7$ & $74.0-431.1$ & $139.9 \pm 41.7$ & 29.1-349.7 \\
\hline & 2012 & $226.7 \pm 36.2$ & $110.5-444.3$ & n.e. & n.e. & $142.3 \pm 38.3$ & $64.3-381.7$ \\
\hline \multirow[t]{2}{*}{ WSC concentration maturity (mg g ${ }^{-1}$ ) } & 2011 & $43.4 \pm 23.2$ & $15.8-171.3$ & $36.4 \pm 26.7$ & $3.7-224.2$ & $17.7 \pm 5.4$ & $7.0-32.7$ \\
\hline & 2012 & $48.5 \pm 18.1$ & $20.7-146.6$ & n.e. & n.e. & $41.7 \pm 17.8$ & $14.7-153.5$ \\
\hline \multirow[t]{2}{*}{ Total WSC content anthesis (mg stem ${ }^{-1}$ ) } & 2011 & $221.5 \pm 91.5$ & 49.8-770.6 & $256.8 \pm 92.3$ & $80.8-758.7$ & $234.9 \pm 95.5$ & $58.6-636.4$ \\
\hline & 2012 & $413.2 \pm 110.5$ & 158.0-988.9 & n.e. & n.e. & $174.2 \pm 73.1$ & $37.8-583.5$ \\
\hline \multirow[t]{2}{*}{ Total WSC content maturity (mg stem ${ }^{-1}$ ) } & 2011 & $30.6 \pm 19.6$ & $7.3-157.7$ & $36.9 \pm 33.0$ & $3.3-291.5$ & $20.2 \pm 8.4$ & $3.2-53.2$ \\
\hline & 2012 & $53.1 \pm 27.7$ & $17.1-169.9$ & n.e. & n.e. & $43.9 \pm 24.7$ & $6.5-195.1$ \\
\hline \multirow[t]{2}{*}{ Kernel $\Delta^{13} \mathrm{C}(0 / 00)$} & 2011 & $14.2 \pm 0.6$ & $11.9-16.3$ & $16.5 \pm 0.9$ & $14.6-19.6$ & $18.1 \pm 0.6$ & $16.2-19.6$ \\
\hline & 2012 & $14.9 \pm 0.4$ & $13.4-16.1$ & n.e. & n.e. & $18.7 \pm 0.4$ & $17.4-20.1$ \\
\hline
\end{tabular}

seasons, whereas for GY, PH, and KM2 was only in one growing season (Table 1). Among the physiological traits, the SPAD index exhibited a significant $(P<0.001)$ GxE interaction in both growing seasons, but stem weight and WSC concentration and content, and $\Delta^{13} \mathrm{C}$ of kernels was only in 2012 (Table 1).

Under FI in Santa Rosa, the average GY of the three sets of wheat genotypes (378 in total) was $8-10 \mathrm{Mg} \mathrm{ha}^{-1}$ but some genotypes produced up to $12 \mathrm{Mg} \mathrm{ha}^{-1}$ (Figure 2A). Under MWS in Santa Rosa the average GY was $4.8 \mathrm{Mg} \mathrm{ha}^{-1}$. Under WS GY was significantly $(P<0.0001)$ reduced in Cauquenes, by 79 and $68 \%$ in 2011 and 2012, respectively, compared to Santa Rosa under FI (Figure 2A). Also, plant height was reduced under WS by 40 and $9 \%$ in 2011 and 2012, respectively (Figure 2B).

The reduction in SM2, KS and TKW under WS compared with FI was in general more pronounced in the first growing season; on average (of the two growing seasons) these traits were reduced by $25,41,21$, and $18 \%$, respectively, whereas KM2 was reduced by $53 \%$ (Figure 3 ).

The relationships for GY under FI and WS showed no significant correlation in both years $(P>0.05)$. The yield tolerance index (YTI) of the 378 genotypes based on GY under WS and FI presented a wide range of values in both years, from 0.05 (very susceptible) to 0.65 (very tolerant genotypes). The frequency distribution of YTI had a left-skewed deviation in 2011 $($ mean YTI $=0.21)$ compared to $2012($ mean YTI $=0.32)$.
Days to heading, determined under FI, differed by about 20 days between the earliest and latest genotypes (Table 2). A wide range of SPAD index values among genotypes was observed in environments (WS, MWS, and FI) and growing seasons (Table 2). A significant reduction $(P<0.001)$ in the SPAD index at anthesis and during grain filling was observed under WS in 2012.

Stem weight and stem WSC concentration and content were much higher at anthesis compared to maturity. Their average reductions over two growing seasons were about 43, 77, and $87 \%$, respectively, under WS at Cauquenes, and 23, 79, and $84 \%$, respectively, in Santa Rosa under FI (Table 2). The apparent WSC remobilization was on average 279, 220, and $170 \mathrm{mg}$ per stem under WS, MWS, and FI, respectively (data not shown).

The WSC concentration and content per stem at anthesis and maturity presented large genotypic variabilities in all the environments (Table 2). The stem WSC per unit area $\left(\mathrm{g} \mathrm{m}^{-2}\right)$ at anthesis was highly correlated to the WSC concentration $(r=$ 0.66 and $0.84, P<0.001$, for WS for FI, respectively, in 2012) and the stem biomass $\left(\mathrm{g} \mathrm{m}^{-2} ; r=0.81\right.$ and $0.66, P<0.001$, for a WS for FI, respectively, in 2012).

The $\Delta^{13} \mathrm{C}$ also exhibited genotypic variability under WS, MWS, and FI (Table 2), but lower values were found under WS compared to FI. 


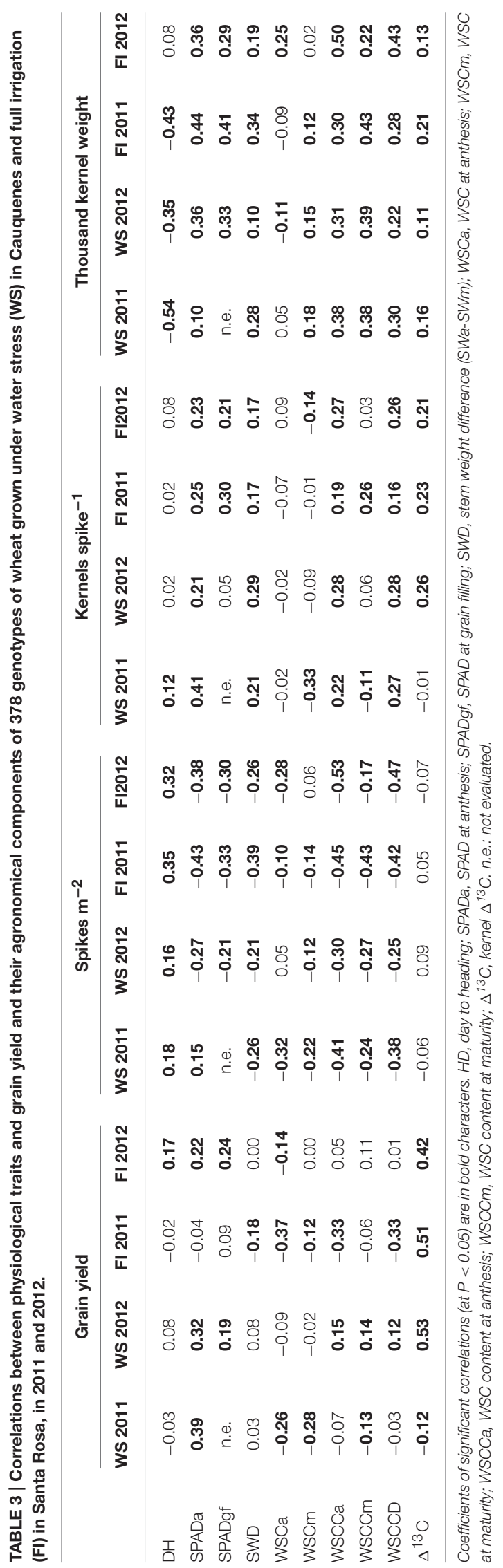

\section{Relationships between Yield, Agronomical, and Physiological Traits}

GY was positively correlated with SM2 and KM2, but negatively correlated with TKW, in both water regimes and growing seasons (Figure 4). GY was also positively correlated $(r=0.3-0.52$, $P<0.001$ ) with plant height in all the environments.

Days to heading (determined at FI) was not correlated with GY, but it was positively correlated with SM2 and negatively correlated with TKW, except under FI in 2012 (Table 3). The SPAD index was positive and significantly correlated with GY (except under FI in 2011) and the agronomical components KS and TKW (Table 3). The WSC content at anthesis (WSCCa) was negatively correlated with SM2, but positively correlated with KS and TKW under WS and FI conditions (Figure 5). As a consequence, GY exhibited a low positive correlation with WSCCa under WS in 2012, and non or negative correlation under FI (Table 3).

The relationship between $\Delta^{13} \mathrm{C}$ and GY was slightly negative under WS in 2011, but positive and highly significant in 2012, and also positive under MWS and FI in 2011 and 2012 (Table 3; Figure 6A). Indeed, Pearson correlation values of the relationship between $\Delta^{13} \mathrm{C}$ vs. GY depended on the environment, increasing from low to medium yields and further declining at higher GY (Figure 6B). The correlation between $\Delta^{13} \mathrm{C}$ and STI under SWS was not significant in 2011 but was positive and significant in $2012(r=0.51 ; P<0.01)$.

PCA analysis indicated that the two first principal components (PC) explained $>50 \%$ of the observed variability, under WS and FI conditions (Figure 7). KS was the agronomical component more close related with GY under WS and FI (except in 2011). Among the physiological traits, $\Delta{ }^{13} \mathrm{C}$ presented the strongest association with GY, except under the severe WS in 2011 (Figure 7). The SPAD index at anthesis was close associated with GY under WS in 2011, but with TKW under WS in 2012 and FI. WSCCa was also close related to TKW in all the environments, and days to heading was associated SM2.

The stepwise regression analysis between GY and related agronomical (SM2, TKW, and KS) and physiological (SPADa, WSCCa, and $\Delta^{13} \mathrm{C}$ ) traits indicated that under water stress conditions, the contribution of the agronomical trails was greater than the physiological ones, but under full irrigation conditions WSCCa and $\Delta^{13} \mathrm{C}$ contributed similarly to the agronomical traits to GY (Table 4).

\section{DISCUSSION}

The set of 378 wheat genotypes tested in this work exhibited a high phenotypic variability for physiological and agronomic traits. The water stress in Cauquenes was very severe as reflected in the low average GY (1.7 $\mathrm{Mg} \mathrm{ha}^{-1}$ in 2011). However, some genotypes were able to produce more than 4 $\mathrm{Mg} \mathrm{ha}{ }^{-1}$ under such WS conditions and showed high values of YTI $(>0.50)$. Actually, YTI was highly correlated $(r>$ $0.92 ; P<0.0001$ in both years) with GY under WS in Cauquenes. Under the full irrigation conditions of Santa Rosa some genotypes achieved extremely high yields $\left(12 \mathrm{Mg} \mathrm{ha}^{-1}\right)$, 


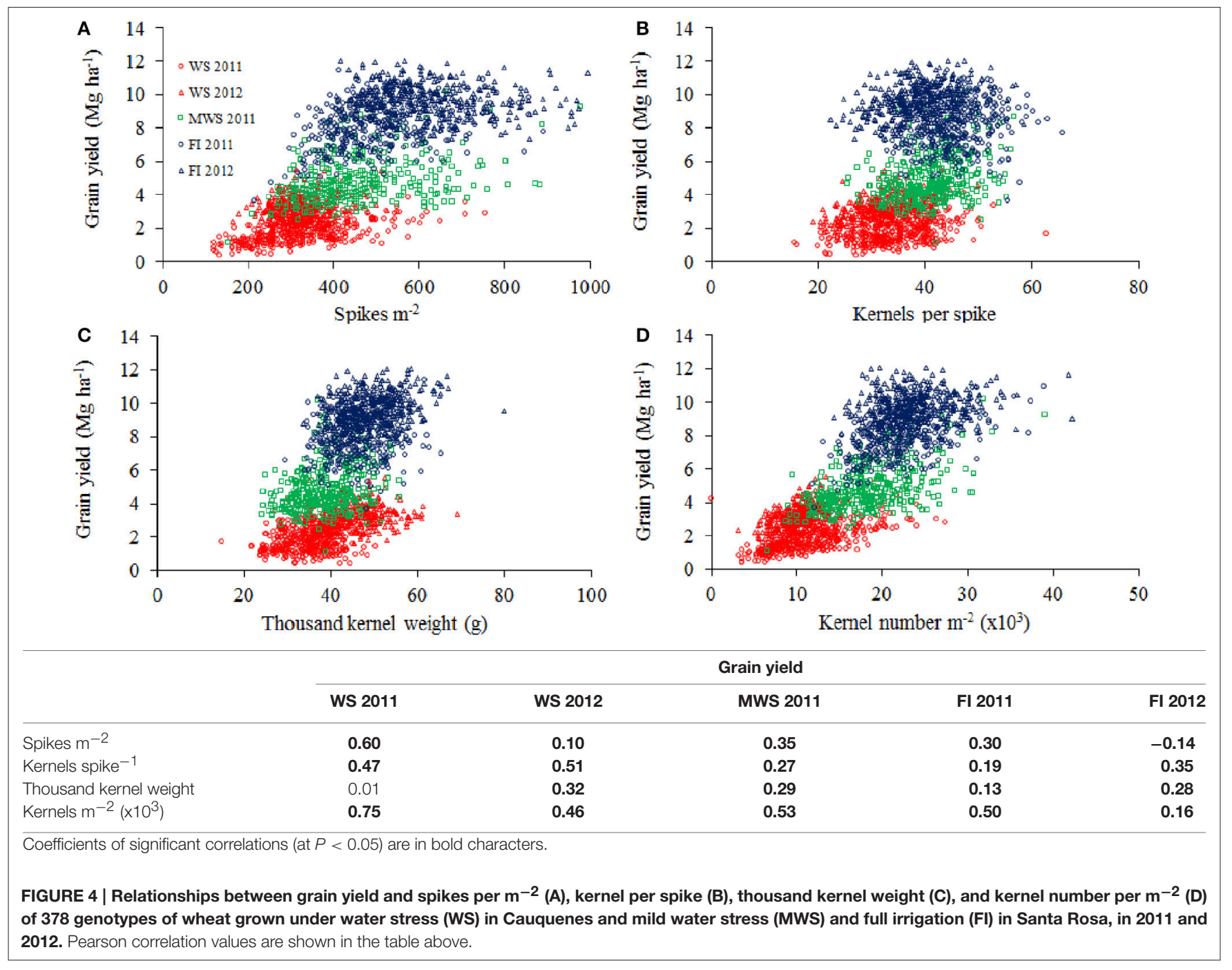

for a Mediterranean environment. Large genotypic variability in GY and its agronomical components has also been found in 127 recombinant inbred lines (Dharwar Dry $\times$ Sitta) of wheat growing under severe water stress in Obregon, Mexico (Kirigwi et al., 2007), and in 105 lines of the double-haploid population (Weebil $\times$ Bacanora) in four contrasting highyielding environments (García et al., 2013).

The strong reduction in GY under WS was mainly a consequence of the decline in SM2 (41\%), followed by KS $(21 \%)$, and as a consequence the number of kernels per $\mathrm{m}^{2}$ was reduced (53\%; Table 2). Thus, kernels per $\mathrm{m}^{2}$ is the agronomical component most affected by drought, as previously reported by other authors (Estrada-Campuzano et al., 2012). In addition the TKW also decreased, but to a lesser extent (18\%). As a consequence GY was positively correlated with the number of kernels $\mathrm{m}^{-2}$ (Figure 4; $r=0.81, P<0.0001$ for all the environments), but the correlation coefficients for each environment were not as high as has been reported by several authors (see Sinclair and Jamieson, 2006). In fact, a trade-off among the agronomical components was observed where SM2 was negatively correlated with KS under FI ( $r=-0.50$ and -0.58 in 2011 and 2012, respectively) and TKW in WS ( $r=-0.36$ and -0.49 in 2011 and 2012, respectively) and FI $(r=-0.60$ and -0.58 in 2011 and 2012, respectively) conditions. The PCA indicated that KS was better associated with GY in both WS and FI conditions (Figure 7). Other studies have also shown that KS but not TKW was associated with GY under water stress conditions (Denčić et al., 2000) and also a high-yielding environment (García et al., 2013).

\section{Chlorophyll Content}

Chlorophyll content at anthesis was positively correlated with GY and the agronomical components KS and TKW, particularly under WS (Table 3). Drought increases senescence by accelerating chlorophyll degradation leading to a decrease in leaf area and photosynthesis. There is evidence that staygreen phenotypes with delayed leaf senescence can improve their performance under drought conditions (Rivero et al., 2007; Lopes and Reynolds, 2012). In wheat and sorghum, genotypic variability has been detected in chlorophyll content as well as in the rate of 

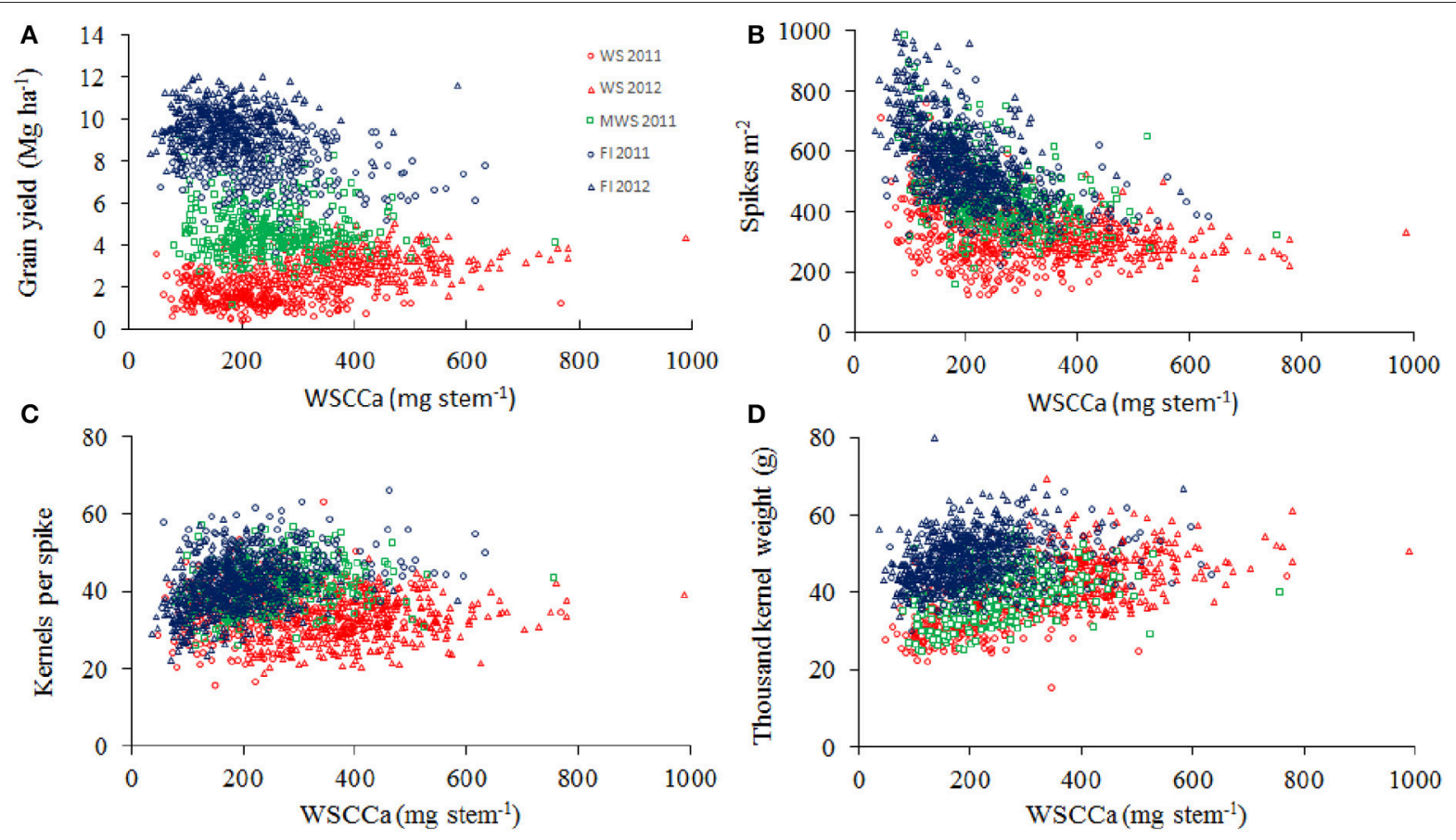

FIGURE 5 | Relationships between stem water-soluble carbohydrate content at anthesis (WSCCa) and grain yield (A), spikes per $\mathrm{m}^{-2}$ (B), kernel per spike (C), and thousand kernel weight (D) in $\mathbf{3 7 8}$ genotypes of wheat grown under water stress (WS) in Cauquenes and mild water stress (MWS) and full irrigation (FI) in Santa Rosa, in 2011 and 2012. Pearson correlation values are in Table $\mathbf{3}$.

TABLE 4 | Stepwise regression analysis between grain yield (GY) and related agronomical (TKW, SM2, and KS) and physiological (SPADa, WSCCa, and $\Delta{ }^{13} \mathrm{C}$ ) traits of 378 genotypes of wheat grown under water stress (WS) in Cauquenes and full irrigation (FI) in Santa Rosa, in 2011 and 2012.

\begin{tabular}{|c|c|c|c|c|c|c|c|c|}
\hline \multirow[b]{2}{*}{ Trait } & \multicolumn{4}{|c|}{ WS 2011-2012 } & \multicolumn{4}{|c|}{ FI 2011-2012 } \\
\hline & Coefficient B & SE & \multicolumn{2}{|c|}{ Contribution } & Coefficient B & SE & \multicolumn{2}{|c|}{ Contribution } \\
\hline Constant & -7.218 & 0.618 & & & -19.270 & 1.138 & & \\
\hline TKW & 0.068 & 0.004 & 30.9 & 13.9 & 0.089 & 0.007 & 16.8 & 8.1 \\
\hline WSCCa & 0.002 & 0.000 & 7.5 & 2.5 & -0.004 & 0.000 & 16.8 & 8.1 \\
\hline$\Delta^{13} \mathrm{C}$ & 0.281 & 0.039 & 6.6 & 2.2 & 0.878 & 0.068 & 18.7 & 9.2 \\
\hline SPADa & -0.026 & 0.005 & 3.4 & 1.1 & 0.051 & 0.011 & 2.8 & 1.2 \\
\hline$R^{2}$ & 0.69 & & & & 0.60 & & & \\
\hline$N$ & 722 & & & & 734 & & & \\
\hline
\end{tabular}

leaf senescence (measured with a portable leaf chlorophyll meter) during grain-filling (Harris et al., 2007; Lopes and Reynolds, 2012). In durum wheat (Triticum turgidum ssp. durum) staygreen mutants growing under glasshouse conditions remained green for longer and had higher rates of leaf photosynthesis and seed weight (Spano et al., 2003). These mutants with the stay-green characteristic also had higher levels of expression of the Rubisco small subunit of (RBCS) and chlorophyll $a / b$ binding protein (Rampino et al., 2006). Bread wheat genotypes with functional stay-green characteristics have also shown higher GY and total biomass in field conditions (Chen et al., 2010). Another study on Canadian spring wheat revealed that GY was positively correlated with green flag leaf duration and total flag leaf photosynthesis (Wang et al., 2008). Studies on spring wheat in the USA found a positive correlation between the staygreen trait and GY and grain weight in both water-limited and 


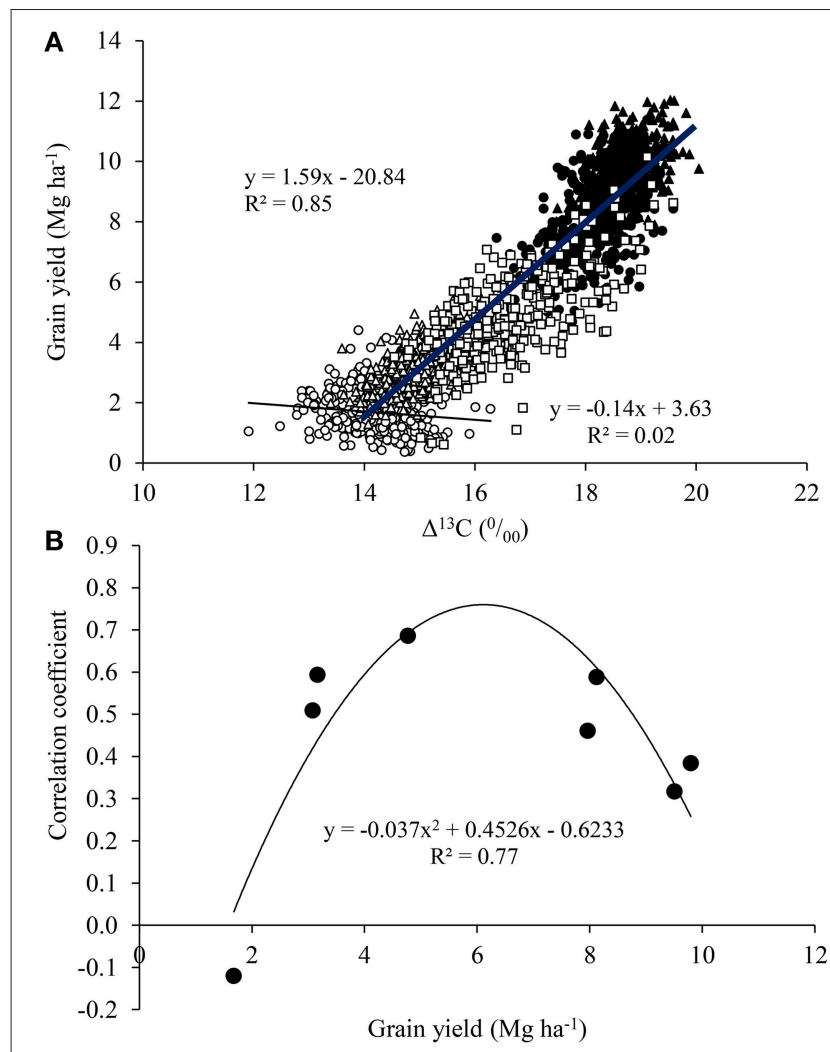

FIGURE 6 | (A) Relationships between grain yield (GY) and carbon discrimination in grains $\left(\Delta^{13} \mathrm{C}\right)$ for the set of 384 spring wheat genotypes grown under water stress $(\bigcirc, \Delta)$, mild water stress $(\square)$ and full irrigation $(\boldsymbol{\bullet}, \mathbf{\Delta})$ conditions in 2011 and 2012. The negative regression is for water stress in 2011 and the positive one is for the rest of the environments. (B) The relationship between GY and correlation coefficients between $G Y$ and $\Delta^{13} \mathrm{C}$ for each replicate (block) and environment (WS, MWS and FI in 2011, and WS and $\mathrm{FI}$ in 2012).

well-watered conditions (Blake et al., 2007). Therefore, a delay in leaf senescence would increase the amount of fixed carbon available for grain filling.

\section{Stem Water-Soluble Carbohydrate}

Large genotypic variability in stem WSC concentration and content was found at anthesis and maturity, in both environments (Table 2; Figure 5). Other studies conducted in spring and winter wheat lines have also found large variability in WSC concentration and WSC content on an area basis in stems around the time of anthesis (Ruuska et al., 2006; Foulkes et al., 2007; Yang et al., 2007). WSCs are accumulated in stems prior to anthesis and are then remobilized to the grain during the grain-filling period (Blum, 1998; Bingham et al., 2007). Indeed under water limiting conditions, where canopy photosynthesis is inhibited, the contribution of stem carbohydrate to grain growth could be very significant (Ehdaie et al., 2006a,b; Reynolds et al., 2006). In our study, more carbohydrate was accumulated at anthesis under WS than under FI, and the decline in stem WSC from anthesis to maturity was greater under WS, particularly in
2012 (360 vs. $130 \mathrm{mg}$ per stem under WS and FI, respectively). This suggests that there was a larger remobilization of reserves during grain filling under WS. However, there were no clear relationships between the stem WSCCa, or the apparent WSC remobilization and GY, varying the correlation values from not significant to negative on the different environments (Table 3; Figure 5). Zhang et al. (2015) found also no significant correlation between stem WSC and GY in 20 genetically diverse double haploids derived from the cross of cvs. Westonia $\times$ Kauz, growing under drought, and irrigated conditions in Western Australia. These results differ from those found by Foulkes et al. (2007) in winter wheat under non water-stressed conditions in England.

It seems that there is a trade-off between the stem WSCCa and some of the agronomical yield components. In fact, negative correlations exist with SM2 in all the environments, but the correlations were positive with KS and TKW (Table 3; Figure 5). The PCA analyses also showed a high association between WSCCa and TKW (Figure 7). This negative relationship between WSC and either number of stems or number spikes per $\mathrm{m}^{2}$ at maturity has also been reported for other wheat genotypes (Rebetzke et al., 2008a; Dreccer et al., 2009, 2013). Why genotypes with lower number of stems present higher stem WSC concentration and content? A possible explanation is that genotypes with lower number of stems per unit area have bigger stems; if fact, our results indicated a significant $(p<0.001)$ negative correlation $(r=-0.29$ and -0.36 under WS, and -0.58 and -0.56 under FI, in 2011 and 2012, respectively) between SM2 and stem weight at anthesis. Thus, genotypes with lower number of stems have probably more light transmission through the canopy and therefore higher rates of photosynthesis per stem, leading to higher stem weight and WSC content (more reserves), and greater numbers of grains per spike and kernel size. A significant and positive correlation between accumulated WSC at anthesis and kernel weight has been also observed in recombinant inbred lines (RILs) from the Seri/Babax population (Dreccer et al., 2009). Another hypothesis (complementary of the previous one) may be that those genotypes able to produce less tillers (because poorer adaptation to growing conditions-such as water stress-) are those which accumulate more carbohydrate since these photoassimilates are not used for growth. Therefore, selecting for high stem WSC, either under near optimal agronomical conditions or under water stress, would probably lead to genotypes with lower tillering capacity and GY potential. The study conducted by Dreccer et al. (2013) in RILs of contrasting tillering and WSC concentration in the stem, and grown at different plant densities or on different sowing dates, indicates that genotypic rankings for stem WSC persisted when RILs were compared at similar stem density.

\section{Carbon Isotope Discrimination}

The genotypic differences in carbon isotope discrimination found among the 384 genotypes (Table 3) agree with other studies conducted in Mediterranean conditions. For example, higher $\Delta^{13} \mathrm{C}$ (or lower carbon isotope composition, $\delta^{13} \mathrm{C}$ ) in modern cultivars compared with old varieties has been found 


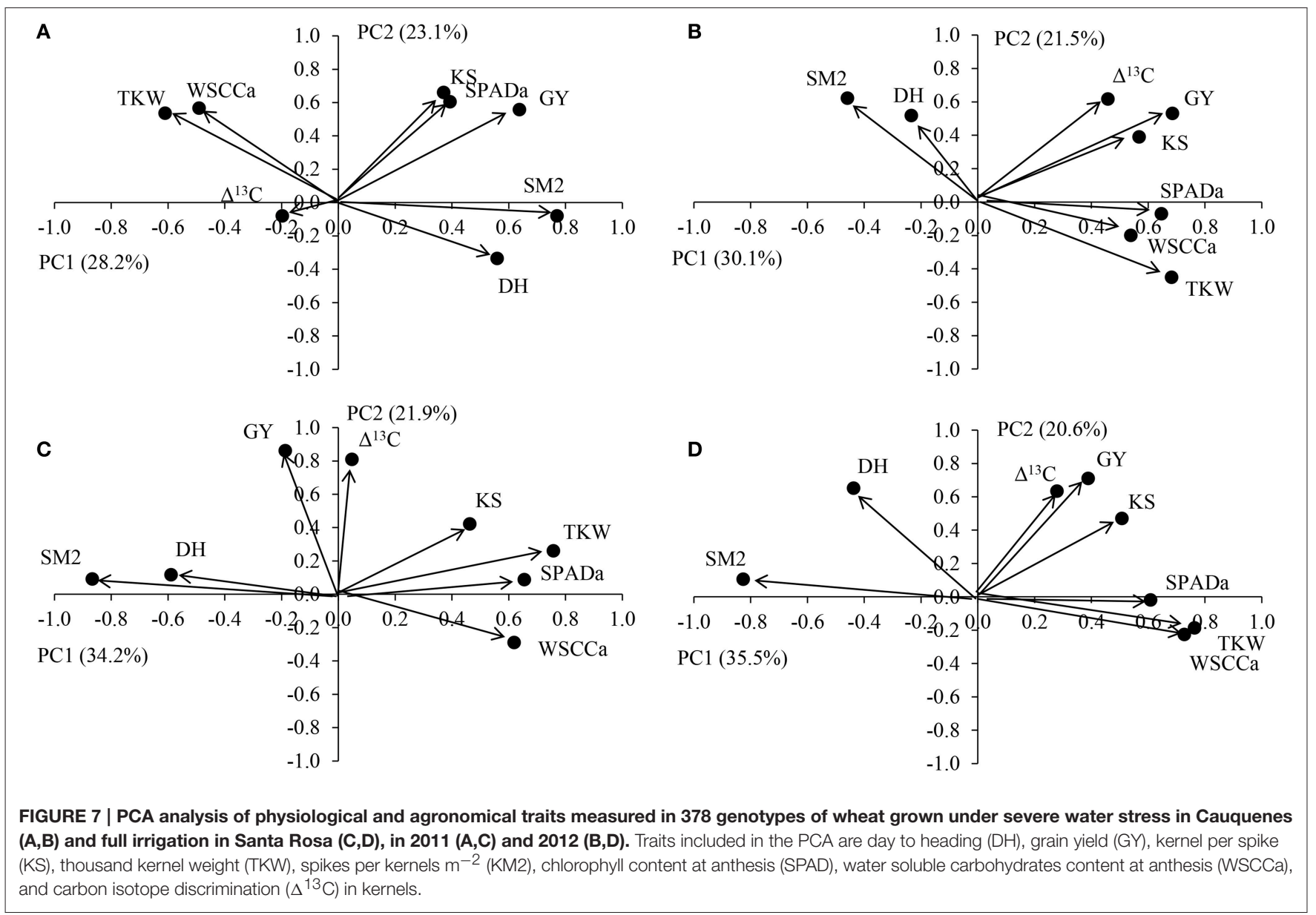

in bread (del Pozo et al., 2014) and durum wheats (Araus et al., 2013).

The relationship between $\triangle 13 \mathrm{C}$ and GY was positive under MWS or FI but was negative under WS (Figure 5). Other studies in wheat (Araus et al., 2003, 2008) and barley (del Pozo et al., 2012) have also shown that $\Delta^{13} \mathrm{C}$ in kernels can be positively or negatively correlated with GY depending on soil water availability. Positive relationships between $\Delta^{13} \mathrm{C}$ (or negative with $\delta^{13} \mathrm{C}$ ) and GY have been frequently reported for cereals under Mediterranean conditions (see Rebetzke et al., 2008b for bread wheat and Araus et al., 2003, 2013 for durum wheat), and this can be explained by the fact that genotypes maintaining a larger transpiration and thus water use during the crop cycle will be the most productive (Araus et al., 2003, 2008, 2013; Blum, $2005,2009)$. In fact, negative relationships between kernel oxygen isotope composition $\left(\delta^{18} \mathrm{O}\right)$ or enrichment $\left(\Delta^{18} \mathrm{O}\right)$ and grain yield have been reported in bread wheat under fully irrigated conditions (Cabrera-Bosquet et al., 2011; del Pozo et al., 2014) as well as for durum wheat under Mediterranean conditions (Araus et al., 2013) and subtropical maize under well irrigated and moderate stress (Cabrera-Bosquet et al., 2009). Indeed, carbon isotope composition can be used as a selection criterion for high water use efficiency (Condon et al., 2004; Richards, 2006), but also can provide an indirect determination of the effective water used by the crop (Araus et al., 2002, 2008; Blum, 2009). The effect of phenology on $\Delta^{13} \mathrm{C}$ (earlier genotypes exhibiting higher $\Delta^{13} \mathrm{C}$ ) may be discarded, since heading date was not correlated with $\Delta^{13} \mathrm{C}(P>0.05)$ in none of the environments. Actually, the positive correlations between $\Delta^{13} \mathrm{C}$ and GY was also found when the relationship were studied within subset of 212 genotypes with similar heading duration (80-85 days); $r=0.50$ for WS and 0.42 for WI in 2012.

\section{CONCLUSIONS}

The identification of genotypic variability for agronomical and physiological traits under water stress conditions and full irrigation is of great interest for breeders because selected genotypes with favorable traits can be used as parents in future crosses. Among these, genotypes with higher numbers of fertile tillers would lead to higher numbers of kernels per $\mathrm{m}^{2}$ and GY under terminal water stress and non-stress conditions. Additionally, genotypes with delay in leaf senescence (a higher SPAD index) would lead to higher KS and TKW, particularly under water stress, and to a lesser extent at full irrigation. In the case of yield potential conditions, this is probably the consequence of greater amounts of fixed carbon available for grain filling, whereas under water stress stay-green it is an indicator of resilience to stress conditions. In addition, genotypes 
with higher carbon discrimination values are associated with higher GY under MWS and full irrigation, indicating that more water is used by the crop. In addition, selection for a higher WSC at anthesis may bring negative consequences in terms of yield potential and adaptation to MWS conditions. This study clearly illustrates the importance of defining the target environment for wheat breeding before determining the set of phenotyping traits for selection.

\section{AUTHOR CONTRIBUTIONS}

$\mathrm{AD}$ and IM designed the experiments, selected the germplasm and participated on field evaluations. AY and GT were in charge of carbohydrate determinations. DC was in charge of the management of the experiments and evaluation of agronomic traits. LS and JA contributed to analysis of the data. AD was in charge of the writing up but all the authors contributed to the manuscript.

\section{REFERENCES}

Acevedo, E., Baginsky, C., Solar, B., and Ceccarelli, S. (1997). Discriminación isotópica de ${ }^{13} \mathrm{C}$ y su relación con el rendimiento y la eficiencia de transpiración de genotipos locales y mejorados de cebada bajo diferentes condiciones hídricas. Inv. Agríc. (Chile) 17, 41-54.

Araus, J. L., Amaro, T., Casadesus, J., Asbati, A., and Nachit, M. M. (1998). Relationships between ash content, carbon isotope discrimination and yield in durum wheat. Aust. J. Plant Phys. 25, 835-842.

Araus, J. L., Cabrera-Bosquet, L., Serret, M. D., Bort, J., and Nieto-Taladriz, M. T. (2013). Comparative performance of $\delta^{13} \mathrm{C}, \delta^{18} \mathrm{O}$ and $\delta^{15} \mathrm{~N}$ for phenotyping durum wheat adaptation to a dryland environment. Funct. Plant Biol. 40, 595-608. doi: 10.1071/FP12254

Araus, J. L., Slafer, G. A., Reynolds, M. P., and Royo, C. (2002). Plant breeding in C3 cereals: what should we look for? Ann. Bot. 89, 925-940. doi: 10.1093/aob/mcf049

Araus, J. L., Slafer, G. A., Royo, C., and Serret, M. D. (2008). Breeding for yield potential and stress adaptation in cereals. Crit. Rev. Plant Sci. 27, 377-412. doi: 10.1080/07352680802467736

Araus, J. L., Villegas, D., Aparicio, L. F., García del Moral, S., El Hani, S., Rharrabti, Y., et al. (2003). Environmental factors determining carbon isotope discrimination and yield in durum wheat under Mediterranean conditions. Crop Sci. 43, 170-180. doi: 10.2135/cropsci2003.1700

Bingham, I. J., Blake, J., Foulkes, M. J., and Spink, J. (2007). Is barley yield in the UK sink limited? Post-anthesis radiation interception, radiationuse efficiency and source-sink balance. Field Crop. Res. 101, 198-211. doi: 10.1016/j.fcr.2006.11.005

Blake, N. K., Lanning, S. P., Martin, J. M., Sherman, J. D., and Talbert, L. E. (2007). Relationship of flag leaf characteristics to economically important traits in two spring wheat crosses. Crop Sci. 47, 491-496. doi: 10.2135/cropsci2006.05.0286

Blum, A. (1998). Improving wheat grain filling under stress by stem reserve mobilisation. Euphytica 100, 77-83. doi: 10.1023/A:1018303922482

Blum, A. (2005). Drought resistance, water-use efficiency, and yield potentialare they compatible, dissonant, or mutually exclusive? Aust. J. Agric. Res. 56, 1159-1168. doi: 10.1071/AR05069

Blum, A. (2009). Effective use of water (EUW) and not water-use efficiency (WUE) is the target of crop yield improvement under drought stress. Field Crop. Res. 112, 119-123. doi: 10.1016/j.fcr.2009.03.009

Cabrera-Bosquet, L., Albrizio, R., Nogués, S., and Araus, J. L. (2011). Dual $\Delta^{13} \mathrm{C} / \delta^{18} \mathrm{O}$ response to water and nitrogen availability and its relationship with yield in field-grown durum wheat. Plant Cell Environ. 34, 418-433. doi: 10.1111/j.1365-3040.2010.02252.x

Cabrera-Bosquet, L., Sánchez, C., and Araus, J. L. (2009). How yield relates to ash content, $\Delta^{13} \mathrm{C}$ and $\Delta^{18} \mathrm{O}$ in maize grown under

\section{ACKNOWLEDGMENTS}

This work was supported by the research CONICYT grants FONDECYT $\mathrm{N}^{\circ} 1150353$ and program "Atracción de Capital Humano Avanzado del Extranjero” N ${ }^{\circ} 80110025$. Participation of JA was supported through the Spanish project AGL2013-44147-R. We thank to CIMMYT and the National Research Program of Rainfed Crops of INIAUruguay for providing wheat germplasm, Alejandra Rodriguez and Alejandro Castro for technical assistance in field experiments, and Boris Muñoz for the analysis of soluble carbohydrates.

\section{SUPPLEMENTARY MATERIAL}

The Supplementary Material for this article can be found online at: http://journal.frontiersin.org/article/10.3389/fpls.2016. 00987

different water regimes. Ann. Bot. 104, 1207-1216. doi: 10.1093/aob/ $\operatorname{mcp} 229$

Calderini, D. F., and Slafer, G. A. (1998). Changes in yield and yield stability in wheat during the 20th Century. Field Crop. Res. 57, 335-347.

Cattivelli, L., Rizza, F., Badeck, F. W., Mazzucotelli, E., Mastrangelo, A. M., Francia, E., et al. (2008). Drought tolerance improvement in crop plants: an integrated view from breeding to genomics. Field Crop. Res. 105, 1-2. doi: 10.1016/j.fcr.2007.07.004

Chen, J. B., Liang, Y., Hu, X. Y., Wang, X. X., Tan, F. Q., Zhang, H. Q., et al. (2010). Physiological characterization of 'stay green' wheat cultivars during the grain filling stage under field growing conditions. Acta Physiol. Plant. 32, 875-882. doi: 10.1007/s11738-010-0475-0

Condon, A. G., Richards, R. A., Rebetzke, G. J., and Farquhar, G. D. (2004). Breeding for high water-use efficiency. J. Exp. Bot. 55, 2447-2460. doi: $10.1093 / \mathrm{jxb} / \mathrm{erh} 277$

Coplen, T. B. (2008). "Explanatory glossary of terms used in Expression of relative isotope ratios and gas Ratios," in IUPAC Recommendations 2008. International Union of Pure and Applied Chemistry Inorganic Chemistry Division. Commission on Isotopic Abundances and Atomic Weights. 27. Available online at: http://media.iupac.org/reports/provisional/abstract08/coplen_prs.pdf

del Pozo, A., Castillo, D., Inostroza, L., Matus, I., Méndez, A. M., and Morcuende, R. (2012). Physiological and yield responses of recombinant chromosome substitution lines of barley to terminal drought in a Mediterraneantype environment. Ann. Appl. Biol. 160, 157-167. doi: 10.1111/j.17447348.2011.00528.x

del Pozo, A., and del Canto, P. (1999). Áreas Agroclimáticas y Sistemas Productivos de la VII y VII región. Instituto de Investigaciones Agropecuarias, Centro de Investigaciones Quilamapu. Serie Quilamapu $\mathrm{N}^{\circ} 113$.

del Pozo, A., Matus, I., Serret, M. D., and Araus, J. L. (2014). Agronomic and physiological traits associated with breeding advances of wheat under highproductive Mediterranean conditions. The case of Chile. Env. Exp. Bot. 103, 180-189. doi: 10.1016/j.envexpbot.2013.09.016

Denčić, S., Kastori, R., Kobiljski, B., and Duggan, B. (2000). Evaluation of grain yield and its components in wheat cultivars and landraces under near optimal and drought conditions. Euphytica 113, 43-52. doi: 10.1023/A:1003997700865

Dreccer, M. F., Chapman, S. C., Rattey, A. R., Neal, J., Song, Y., Christopher, J. T., et al. (2013). Developmental and growth controls of tillering and water-soluble car-bohydrate accumulation in contrasting wheat (Triticum aestivum L.) genotypes:can we dissect them? J. Exp. Bot. 64, 143-160. doi: $10.1093 /$ jxb/ers317

Dreccer, M., Van Herwaarden, A., and Chapman, S. (2009). Grain number and grain weight in wheat lines contrasting for stem water soluble carbohydrate concentration. Field Crop. Res. 112, 43-54. doi: 10.1016/j.fcr.2009.02.006 
Ehdaie, B., Alloush, G. A., Madore, M. A., and Waines, J. G. (2006a). Genotypic variation for stem reserves and mobilization in wheat: I. postanthesis changes in internode dry matter. Crop Sci. 46, 735-746. doi: 10.2135/cropsci2005.04-0033

Ehdaie, B., Alloush, G. A., Madore, M. A., and Waines, J. G. (2006b). Genotypic variation for stem reserves and mobilization in wheat: II. postanthesis changes in internode water-soluble carbohydrates. Crop Sci. 46, 2093-2103. doi: 10.2135/cropsci2006.01.0013

Engler, A., and del Pozo, A. (2013). Assessing long and short run trends in cereal yields: the case of Chile between 1929-2009. Cien. Inv. Agr. 40, 397-410. doi: 10.4067/S0718-16202013000100005

Estrada-Campuzano, G., Slafer, G. A., and Miralles, D. (2012). Differences in yield, biomass and their components between triticale and wheat grown under contrasting water and nitrogen environments. Field Crop. Res. 128, 167-179. doi: 10.1016/j.fcr.2012.01.003

Farquhar, G. D., Ehleringer, J. R., and Hubick, K. T. (1989). Carbon isotope discrimination and photosynthesis. Annu. Rev. Plant Phys. 40, 503-537.

Fischer, R. A. (2007). Understanding the physiological basis of yield potential in wheat. J. Agric. Sci. 145, 99-113. doi: 10.1017/S0021859607006843

Fischer, R. A., and Edmeades, G. O. (2010). Breeding and cereal yield progress. Crop Sci. 50, S85-S98. doi: 10.2135/cropsci2009.10.0564

Fleury, D., Jefferies, S., Kuchel, H., and Langridge, P. (2010). Genetic and genomic tools to improve drought tolerance in wheat. J. Exp. Bot. 61, 3211-3222. doi: $10.1093 /$ jxb/erq152

Foulkes, M. J., Snape, J. W., Shearman, V. J., Reynolds, M. P., Gaju, O., and Sylverstar-Bradley, R. (2007). Genetic progress in yield potential in wheat: recent advances and future prospects. J. Agric. Sci. 145, 17-29. doi: $10.1017 /$ S0021859607006740

García, G. A., Hasan, A. K., Puhl, L. E., Reynolds, M. P., Calderini, D. F., and Miralles, D. J. (2013). Grain yield potential strategies in an elite wheat double-haploid population grown in contrasting environments. Crop Sci. 53, 2577-2587. doi: 10.2135/cropsci2012.11.0669

Harris, K., Subudhi, P. K., Borrel, A., Jordan, D., Rosenow, D., Nguyen, H., et al. (2007). Sorghum stay-green QTL individually reduce post-flowering droughtinduced leaf senescence. J. Exp. Bot. 58, 327-338. doi: 10.1093/jxb/erl225

Hawkesford, M., Araus, J., Park, R., Calderini, D., Miralles, D., Shen, T., et al. (2013). Prospects of doubling global wheat yields. Food Energy Secur. 2, 34-48. doi: 10.1002/fes3.15

Kirigwi, F. M., Van Ginkel, M., Brown-Guedira, G., Gill, B. S., Paulsen, G. M., and Fritz, A. K. (2007). Markers associated with a QTL for grain yield in wheat under drought. Mol. Breeding 20, 401-413. doi: 10.1007/s11032-007-9100-3

Lobell, D. B., Burke, M. B., Tebaldi, C., Mastrandrea, M. D., Falcon, W. P., and Naylor, R. L. (2008). Priorizing climate change adaptation needs for food security in 2030. Science 319, 607-610. doi: 10.1126/science.1152339

Lobell, D. B., and Gourdji, S. M. (2012). The influence of climate change on global crop productivity. Plant Physiol. 160, 1686-1697. doi: 10.1104/pp.112.208298

Lopes, M. S., and Reynolds, M. P. (2012). Stay-green in spring wheat can be determined by spectral reflectance measurements (normalized difference vegetation index) independently from phenology. J. Exp. Bot. 63, 3789-3798. doi: $10.1093 /$ jxb/ers071

Matus, I., Mellado, M., Pinares, M., Madariaga, R., and del Pozo, A. (2012). Genetic progress in winter wheat cultivars released in Chile from 1920 and 2000. Chil. J. Agr. Res. 72, 303-308. doi: 10.4067/S0718-58392012000300001

Nouri, A., Etminan, A., Teixeira da Silva, J. A., and Mohammadi, R. (2011). Assessment of yield, yield-related traits and drought tolerance of durum wheat genotypes (Triticum turjidum var. durum Desf.). Aust. J. Crop Sci. 5, 8-16.

Ober, E. S., Clark, C. J. A., Le Bloa, M., Royal, A., Jaggard, K. W., and Pidgeon, J. D. (2004). Assessing the genetic resources to improve drought tolerance in sugar beet: agronomic traits of diverse genotypes under droughted and irrigated condition. Field Crop. Res. 90, 213-234. doi: 10.1016/j.fcr.2004.03.004

Rampino, P., Spano, G., Pataleo, S., Mita, G., Napier, J. A., Di Fonzo, N., et al. (2006). Molecular analysis of a durum wheat 'stay green' mutant: Expression pattern of photosynthesis-related genes. J. Cereal Sci. 43, 160-168. doi: $10.1016 /$ j.jcs.2005.07.004

Rebetzke, G. J., Condon, A. G., Farquhar, G. D., Appels, R., and Richards, R. A. (2008b). Quantitative trait loci for carbon isotope discrimination are repeatable across environments and wheat mapping populations. Theor. Appl. Genet. 118, 123-137. doi: 10.1007/s00122-008-0882-4
Rebetzke, G. J., van Herwaarden, A. F., Jenkeins, C., Weiss, M., Lewis, D., Ruuska, S., et al. (2008a). Quantitative trait loci for water-soluble carbohydrates and associations with agronomic traits in wheat. Aust. J. Exp. Agric. 59, 891-905. doi: 10.1071/AR08067

Reynolds, M., Dreccer, F., and Trethowan, R. (2006). Drought-adaptive traits derived from wheat wild relatives and landraces. J. Exp. Bot. 58, 177-186. doi: $10.1093 / \mathrm{jxb} / \mathrm{erl} 250$

Richards, R. A. (2006). Physiological traits used in the breeding of new cultivars for water-scarce environments. Agric. Water Manag. 80, 197-211. doi: 10.1016/j.agwat.2005.07.013

Richards, R. A., Rebetzke, G. J., Condon, A. G., and Herwaarden, A. F. V. (2002). Breeding opportunities for increasing the efficiency of water use and crop yield in temperate cereals. Crop Sci. 42, 111-121. doi: 10.2135/cropsci2002.0111

Rivero, R. M., Kojima, M., Gepstein, A., Sakakibara, H., Mittler, R., Gepstein, S., et al. (2007). Delayed leaf senescence induces extreme drought tolerance in a flowering plant. Proc. Natl. Acad. Sci. U.S.A. 104, 19631-19636. doi: 10.1073/pnas.0709453104

Ruuska, S., Rebetzke, G., Van Harwaarden, A., Richards, R., Fettel, N., Tabe, L., et al. (2006). Genotypic variation in wheat. Funct. Plant Biol. 33, 799-809. doi: 10.1071/FP06062

Sánchez-García, M., Royo, C., Aparicio, N., Martín-Sánchez, A., and Álvaro, F. (2013). Genetic improvement of bread wheat yield and associated traits in Spain during the 20th century. J. Agric. Sci. 151, 105-118. doi: $10.1017 /$ S0021859612000330

Sinclair, T. R., and Jamieson, P. D. (2006). Grain number, wheat yield, and bottling beer: an analysis. Field Crop. Res. 98, 60-67. doi: 10.1016/j.fcr.2005.12.006

Spano, G., Di Fonzo, N., Perrotta, C., Platani, C., Ronga, G., Lawlor, D. W., et al. (2003). Physiological characterization of 'stay green' mutants in durum wheat. J. Exp. Bot. 54, 1415-1420. doi: 10.1093/jxb/erg150

Tambussi, E. A., Bort, J., and Araus, J. L. (2007). Water use efficiency in C3 cereals under Mediterranean conditions: a review of physiological aspects. Ann. Appl. Biol. 150, 307-321. doi: 10.1111/j.1744-7348.2007.00143.x

Voltas, J., Romagosa, I., Lafarga, A., Armesto, A. P., Sombrero, A., and Araus, J. L. (1999). Genotype by environment interaction for grain yield and carbon isotope discrimination of barley in Mediterranean Spain. Crop Pasture Sci. 50, 1263-1271.

Wang, H., McCaig, T. N., Depauw, R. M., and Clarke, J. M. (2008). Flag Leaf physiological traits in two high-yielding Canada Western Red Spring wheat cultivars. Can. J. Plant Sci. 88, 35-42. doi: 10.4141/CJPS07055

Yang, D., Jing, R., Chang, X., and Li, W. (2007). Identification of quantitative trait loci and environmental interactions for accumulation and remobilization of water-soluble carbohydrates in wheat (Triticum aestivum L.) stems. Genetics 176, 571-584. doi: 10.1534/genetics.106.068361

Yemm, E. W., and Willis, A. J. (1954). The estimation of carbohydrates in plant extracts by anthrone. Biochem. J. 57, 508-514.

Zadoks, J. C., Chang, T. T., and Konzak, C. F. (1974). A decimal code for the growth stages of cereals. Weed Res. 14, 415-421.

Zhang, J., Xu, Y., Chen, W., Dell, B., Vergauwen, R., Biddulph, B., et al. (2015). A wheat 1-FEH w3 variant underlies enzyme activity for stem WSC remobilization to grain under drought. New Phytol. 205, 293-305. doi: 10.1111/nph.13030

Zhou, Y., He, Z. H., Chen, X. M., Wang, D. S., Yan, J., Xia, X. C., et al. (2007). "Genetic improvement of wheat yield potential in North China," in Wheat Production in Stressed Environments, eds H. T. Buck, J. E. Nisi, and N. Salomón (New York, NY: Springer-Verlag), 583-589.

Conflict of Interest Statement: The authors declare that the research was conducted in the absence of any commercial or financial relationships that could be construed as a potential conflict of interest.

Copyright (c) 2016 del Pozo, Yáñez, Matus, Tapia, Castillo, Sanchez-Jardón and Araus. This is an open-access article distributed under the terms of the Creative Commons Attribution License (CC BY). The use, distribution or reproduction in other forums is permitted, provided the original author(s) or licensor are credited and that the original publication in this journal is cited, in accordance with accepted academic practice. No use, distribution or reproduction is permitted which does not comply with these terms. 